\title{
The Reconstruction of Cash Management System of Yunhai Group under the Network Environment
}

\author{
Wenhao $\operatorname{Tan}^{1, \mathrm{a}}$, Wenxuan $\operatorname{Tan}^{2, \mathrm{~b},{ }^{*}}$ \\ ${ }^{1}$ School of Accounting, Nanjing University of Finance and Economics, Nanjing 200019, China; \\ ${ }^{2}$ International Audit School, Nanjing University of Audit, Nanjing 200024, China \\ a twhanenao@163.com, bismakr54@163.com
}

Keywords: Network environment; cash management; system; reconstruction

\begin{abstract}
The emergence of network environment puts forward a new subject for the cash management of conglomerate. To keep pace with the environment reforming, conglomerate should reform the traditional cash management by deeply analyzing the new features of network environment and the new requirements of cash management. After doing that, conglomerate can clearly define the new mechanism of cash operation under network environment and launch the significant reforming to the traditional cash operation system. Taking Yunhai Group as the object of case study, this paper will make a comprehensive analysis on merits and demerits of the previous cash management system. This paper aims at constructing the comprehensive cash management system which will be carried out under the network environment. As a consequence, it will provide effective cash source supporting for the healthy and sustainable development of corporation.
\end{abstract}

\section{Introduction}

The current economic environment has changed, which will challenge the traditional cash management theory and puts forward a new research propositions to cash management model. Under the network background, we should seriously study the characteristics of information network environment and its comprehensive effects on cash management of corporation. After the thorough research on new requirements set up by information network environment on cash management along with the cash management requirements, a corresponding cash management theory will be constructed to provide effective improvement ideas to cash management of corporation.

\section{Challenges made by network environment on cash management of group}

Network environment differs from traditional corporation operating environment on many outer changes $^{[1]}$. A series of involution and innovation take place in many aspects of corporation operating, ranging from field reforming to operating models to operating methods. In particular, network environment offers new operating technologies and ideas to corporation operating management, which can break the limits set up by traditional space and time ideas.

\subsection{The new features of cash management in group under the network circumstance}

The requirement of cash management in group under the network circumstance largely differs from that under the traditional environment. We should construct an effective cash management system which accords with the requirements made by the new environment, which is based on analyzing the new features.

\subsubsection{Significant changes in cash asset allocation structure}

E-currency has been a trend under E-commerce environment. The most profound effect brought by this trend on cash constructing project is that less and less cash will be used. Fund in float capital project will disappear with the increasing development of telecom technology. Therefore, the proportion of fund in float capital in corporation cash project will gradually decrease and finally disappear from human's vision, as the widely use of advanced technology in E-commerce. 


\subsubsection{Strategy changes in cash management}

With the application of E-commerce, electronical payment method will largely reduce the chances of exploiting and managing the phytoplankton cash account for corporation and eliminate the applicable environment and condition of phytoplankton cash. Therefore corporation is less likely to make use of phytoplankton cash account by trying to postpone payment. As an effective method of improving the efficiency of cash using under the traditional circumstance, phytoplankton cash will lose its function under E-commerce circumstance. These new changes on circumstance will make a significant influence on cash management in group ${ }^{[2]}$. It requires group to transform the traditional strategy on cash management for the purpose of improve the efficiency of cash management.

\subsection{The new requirements put forward by network environment on cash management in} Yunhai Group

According to the above analysis, network environment put forward new requirements to cash management in Yunhai Group. The group should seriously analyze the core essence of these requirements in order to make proper reforming on the present cash management system.

\subsubsection{Emphasizing making the cash management keep pace with the whole operating of corporation}

As a key part of corporation management, cash management plays an essential role in the process of normal operating of the corporation. From the point of into consideration, although it is a significant branch system in corporation management, we should associate the cash management with the whole operating management to realize the synchronization operation of the two managements taking the goal of the whole operating.

\subsubsection{To improve the efficiency of allocating cash asset under the network environment}

The allocation of cash asset should seek a dynamic balance between the safety and profit in cash asset. It's not necessarily to allocate the cash asset from the point of monetary asset in accounting. Instead, we should optimize its asset structure under the network environment; cash management in corporation should pay attention to the amount of profit of cash asset and to the improvement of efficiency in cash asset, on the condition of ensuring the cash to be relatively safe and sound.

\section{The construct of cash management system in Yunhai group under the network environment}

From the above analysis, we can learn that the overall efficiency of cash management in Yunhai Group is relatively low. Especially, the coming of network environment brings up with more new challenges to it. Therefore, it is necessary to reconstruct the cash management system to make it suitable to the cash asset operating in order to efficiently cope with the effect by the new environment.

\subsection{The basic ideas of constructing the cash management system in Yunhai Group under the network environment}

The reconstructing of cash management in Yunhai Group should associate its features and requirements with the network environment. Theoretically speaking, construct in the star-style cash management system needs to define its guidelines and features and goals from the point of strategically management.

The key concept of constructing star-style cash management system lies in strengthening the function of cash creating center and defining its headship position in cash management system. The core of star-style means that one centre much closely related system support together ${ }^{[3]}$. A strategically situation of "one center, multi-systems" is formed. The cash asset operating department is not only a checking department. The cash asset operation will be an important supporting point of the group, which can make the cash asset more safe and effective.

\subsection{The focuses of constructing cash management system in Yunhai Group under network environment}

As for Yunhai Group, it should take the exiting problems of its own into consideration in order to establish the cash management system which accords with its overall development. 


\subsubsection{Making clear of the overall requirements on cash management}

As a part of overall operating in group, cash management should be accord with the overall development goal. According to management theory, the cash management goal should be bounded by the overall corporation goal. In other words, it is a manifestation of the overall corporation goal in the part of cash management. The overall goal in group is fixed and is the largest operation goal $^{[4]}$. It means that all the management details should give in this overall goal. If the goal of cash management conflicts with the overall development goal of the group, adjustment should be made in order to achieve the overall development goal. The cash management system will be carried out and operated effectively if it pursues the overall development goal. It also can play the role of supporting the group to develop sustainably and healthily.

\subsubsection{Making fusion between cash asset management and risk management}

Cash management in group should pay attention to keeping the balance among the flow and profit and safety of cash asset. In business practice, more emphasis is paid to the profit of asset operating while the safety management is ignored. It is necessary to fuse the cash asset management system with the risk management during the process of reconstructing cash management system in Yunhai Group. To be specific, it requires introducing the idea of risk management into cash management system and set up the effective risk-warning model for the purpose of healthily operate the cash asset.

\subsubsection{Start-end supervision and quality evaluation are focused}

The cash asset operation exist the whole process of the corporation operating. It is the blood to corporation operating. It determines whether the corporation will develop sustainably and healthily. Therefore it is much necessary to keep eyes on the operating quality of cash asset. An outstanding feature of constructing the star-style cash management system in Yunhai Group is that it enforces the idea of supervision and evaluation to go on steadily. The effective node-control can be seen in the system constructing and operation supervision and organization setting and operation quality evaluation $^{[5]}$. It takes its role of supervision and controlling. On one hand, it can strengthen the operating supervision and controlling. On the other hand, it puts emphasis on the operating quality of cash asset and timely adjusting and optimizing the operating situation which may away from the fixed goal. As a result, it makes sure the efficiency and quality of cash asset operation.

\section{The effects and enlightenments}

The Yunhai Group makes effective measures on the previous cash management system which meets the requirement of network environment. According to the evaluation on the operating goal, it proves that the revised cash management system is effective and scientific. The necessity and realistic meaning of reforming the cash management system under network environment can be recognized. It also provides a useful model for the other corporation to reform the cash management system.

\subsection{Evaluating the effects of reconstructing the cash management system in Yunhai Group}

Reconstructing the cash management system under network environment meets the requirements of network environment on Yunhai group. Many facts prove that, it is an effective framework of cash management in Yunhai Group, such as , optimizing the allocation of cash asset, defining the copyright structure of cash asset, improving the operation efficiency of cash asset .

\subsubsection{Effectively optimize the cash flow structure}

Compared with the same periods in history, the rate of cash flow in operating activity and the rate of net cash flow in money collecting activity has been on the decline, however, the rate of cash flow in investing activity has increased. The ability to be profitable in cash asset has been enhanced. It makes the Yunhai Group finance easily, which weakens the scale and cost of outer financing and effectively improves the structure of cash flow. The improvement in the structure of cash flow means that the goal of allocating cash asset is truly achieved ${ }^{[6]}$. The cash flow gradually achieves the set goal, which also proves that the reconstructing of cash management system in Yunhai Group take effects. 


\subsubsection{Better improvement in the ability of asset operation}

The turnover rate of with that in June of 2010, whose figure is 7.45 , the turnover speed has exceeded 24.43 percent. The increase in the turnover rate of accounts receivable benefits from the optimized mechanism in cash management in Yunhai Group and the strategy aims at accelerating taking back the accounts receivable. A big increase in turnover rate of total asset in corporation demonstrates that the reforming in cash management system in Yunhai Group promotes the operating ability in the total asset and efficiently improves the ability to operate asset and its using rate.

\subsubsection{Both the corporation's value and the benefits of stockholders improved}

The profit rate of net asset of Yunhai Group in 2011 has gained more obvious improvement than that in 2010. The net asset profit rate in the sixth month of 2011 has reached 0.11 . Compared with the figure of 0.08 in the sixth month in 2010, an increase of 37.5 percent has reached. Although there isn't a big increase in figure, we should realize that the net asset invested by the stockholders maintained and increased, which effectively guarantee the legal interest of stockholders. The wealth of stockholders increased. As a result, it promotes the improvement of the corporation value, which helps to the sustainable development of Yunhai Group. From the prospective of sustainability in operation ability, the effective improvement in profit ability proves that the reforming in cash management in Yunhai Group is effective.

\subsection{The enlightened shown in reconstructing cash management system in Yunhai Group}

According to the above analysis of cash management in Yunhai Group, it conducts the reconstructing by taking the following into consideration, namely, the basic principles of reconstructing cash management under the network environment, the unique features of its cash management and so on. The successful implementation of reconstructing cash management in Yunhai Group sets a good example for other corporations to conduct cash management under network environment.

\subsubsection{The cash management system in corporation should take the integration effect}

The cash management system in corporation is an interrelated system which needs cooperation to act as an entity ${ }^{[7]}$. The management system of any corporation, especially the cash management system should pay more attention to the connection with other systems. Associating the individual system function with the whole system function can maximize their functions.

\subsubsection{The cash management system in corporation under the network environment should emphasize the instantaneity}

Under the network environment, the cash management system in corporation should emphasize the instantaneity. The cash management is required to provide the related data timely. Meanwhile, the expansion of corporation in scale also needs the operation data which is real-time. Taking the above points into consideration, corporation should construct the cash management system which is based on the information network.

\subsubsection{To balance the allocation structure of cash asset and profitability}

There are various kinds of asset in corporation, however, non-liquid asset has strong profitability and liquid asset has less profitability. That feature can be obviously seen in cash asset management. Therefore, the reconstructing of cash management system under network environment for Yunhai Group should pay much attention to how to balance the allocation of cash asset and profitability. What it should seek is the balance point among the safety and the liquidity and profitability of allocating the cash asset rather than the maximal profit or the best safety or liquidity.

\section{Conclusion}

With the cash management system, the headquarters can allocate internal fund more efficiently. The maximal function of the corporation can be realized only by fulfilling the function of the individuals. The corporation should strengthen its member's coordination skill on cash flow. The corporation should reasonably solve the asset problems existing in member corporations by adjusting its the present cash asset allocation and cash use limit, for example, the problem of shortage of cash. It makes the cash asset operation be dynamic balance for the Group. What's more, 
the adjustment and allocation of capital is measured by efficiency and profit, which is an operation method of the market.

\section{Reference}

[1]. Guo Haifang. How to strengthen the operating capital management in corporation. Finance and Accounting (In Chinese), 2008, vol.10.pp.48.

[2]. Huang Yongjian. An analysis of constructing the effect evaluation index system of cash management in corporation. Academic Journal of Hunan Junior College of Finance and Economics (In Chinese), 2010, vol.26.pp.118-120.

[3]. Wang Wenfeng.Guo Wenyan. Analyze the cash flow management in corporation from the perspective of finance. Finance and Accounting, 2008, vol.06.pp.23-24.

[4]. Manos R, Murinde V, Green C J. Leverage and Business Groups: Evidence from Indian Firms. Journal of Economics and Business, 2007, Vol.59(5): pp.443-465.

[5]. Buchuk D, Larrain B, Muñoz F, Et Al. the internal Capital Markets of Business Groups: Evidence from intra-Group Loans. Journal of Financial Economics, 2014, Vol.112(2).pp.190-212.

[6]. Adams L, Drtina R. Transfer Pricing For Aligning Divisional and Corporate Decisions. Business Horizons, 2008, Vol.51 (5).pp.411-417.

[7]. Hart S L. A Natural-Resource-Based View of the Firm. The Academy of Management Review, 1995, Vol.20(4).pp. 986-1014. 